\title{
Speed Estimation Air-gap Field-orientation-controlled Induction Motor Drive with Fuzzy Logic Control Flux Observer
}

\author{
Yung-Chang Luo, ${ }^{*}$ Yu-Hsiang Chen, and Ying-Piao Kuo \\ Department of Electrical Engineering, National Chin-Yi University of Technology, \\ No. 57, Sec 2, Zhongshan Rd, Taiping Dist, Taichung 41170, Taiwan (ROC)
}

(Received June 5, 2018; accepted October 10, 2018)

Keywords: speed estimation, flux observer, Hall Effect current sensor, fuzzy logic control (FLC), air-gap field orientation control (AFOC), induction motor (IM) drive

In this paper, a speed estimation method is presented, which is based on a flux observer for air-gap field orientation control (AFOC) of an induction motor (IM) drive that utilizes both air-gap flux and stator current. The stator current is obtained using Hall effect current sensors. The air-gap flux observer design was established using the Lyapunov stability theory, and the estimated rotor speed was derived from the developed flux estimator. The gain matrix parameters of the observer were adjusted by a fuzzy logic control (FLC) strategy. The MATLAB $\backslash$ Simulink ${ }^{\circledR}$ toolbox was used to simulate this system and all the control algorithms were realized using a TI DSP 6713-and-F2812 card to generate pulse-width modulation (PWM) signals for the power stage to actuate the motor and validate the approach. Both the simulations and experimental results verified the effectiveness of the proposed system.

\section{Introduction}

The development of intelligent machines demands very good motor drive control to ensure accuracy and precision. Although AC induction motors (IMs) are robust, inexpensive, suitable for use in harsh environments, and require little maintenance, they are more difficult to control than DC motors because their mathematical model is nonlinearly coupled and time-variant. When the field orientation control (FOC) technique is applied to IMs ${ }^{(1)}$ the complicated mathematical model of an IM can be distributed into flux- and torque-current components. Both components are orthogonal and independently controlled, and a maximum torque-tocurrent ratio can be achieved. The FOC IM drive can be classified into the rotor, stator, and air-gap types. In the rotor FOC, the rotor flux and the stator current are selected as the state variables. ${ }^{(2,3)}$ In the stator FOC, the flux and current of the stator are selected as the state variables. ${ }^{(4,5)}$ In the air-gap FOC, the air-gap flux and the stator current are selected as the state variables. Most of the studies done on the FOC of IM drives have been focused on the rotor and stator. Less attention has been paid to the air-gap FOC (AFOC). The normal implementation of a conventional FOC for an IM drive requires that a position sensor, such as an encoder or

*Corresponding author: e-mail: luoyc@ncut.edu.tw https://doi.org/10.18494/SAM.2019.2020 
a resolver, be used to detect the shaft position. However, the presence of this sensor makes a motor drive less robust and unsuitable for a hostile environment. Hence, the development of a speed estimation scheme in place of this sensor is required for a speed estimation FOC IM drive. Several speed estimation schemes of the speed estimation FOC IM have been published: speed estimation based on the electromotive force of a motor or a flux estimator, ${ }^{(6-9)}$ speed determination from fuzzy logic control (FLC) or a neural network, ${ }^{(10-13)}$ speed identification by an adaptive control system, ${ }^{(14-17)}$ and speed adjustment using an extended Kalman filter. ${ }^{(18-21)}$ In this study, the estimated rotor speed of an AFOC IM drive was derived using the proposed air-gap flux observer, which was designed utilizing the Lyapunov stability theory. This method has advantages over the others in that it is stable, has a simple structure, and is easy to implement. The FLC strategy was used to adjust the gain matrix parameters of the air-gap flux observer because it has been developed using imprecise linguistic knowledge from human experts and is very suitable for a variant condition. Hall effect current sensors were used to measure the IM stator current in the implementation of this AFOC IM drive and air-gap flux observer.

This paper has four sections. In Sect. 1, the research background, motivation, and a literature review of speed estimation methods for FOC IM drives are presented. The decoupled AFOC IM drive system used in this study is covered in Sect. 2. The air-gap flux observer design, based on the Lyapunov stability theory and the use of FLC to acquire the observer gain matrix parameters, is described in Sect. 3. The simulations and experiments are discussed in Sect. 4.

\section{AFOC IM Drive}

The stator and rotor voltage equations of an IM are expressed using the stator current and air-gap flux at the synchronous reference coordinate frame ${ }^{(22)}$ given by

$$
\begin{gathered}
\vec{v}_{s}^{e}=\left(R_{s}+j \omega_{e} L_{s l}+L_{s l} p\right) \vec{i}_{s}^{e}+\left(j \omega_{e}+p\right) \vec{\lambda}_{a g}^{e}, \\
0=\left(R_{r}+j \omega_{s l} L_{r l}+L_{r l} p\right) \vec{i}_{s}^{e}-\frac{1}{L_{m}}\left(R_{r}+j \omega_{s l} L_{r}+L_{r} p\right) \vec{\lambda}_{a g}^{e},
\end{gathered}
$$

where " $j$ " is the imaginary part, $\vec{v}_{s}^{e}=v_{d s}^{e}+j v_{q s}^{e}$ and $\vec{i}_{s}^{e}=i_{d s}^{e}+j i_{q s}^{e}$ are the stator voltage and current, respectively, and $\vec{\lambda}_{a g}^{e}=\lambda_{\text {dag }}^{e}+j \lambda_{\text {qag }}^{e}$ is the air-gap flux. $R_{S}$ and $R_{r}$ are the stator and rotor resistances, $L_{s}, L_{r}$, and $L_{m}$ are the stator, rotor, and mutual inductances, and $L_{s l}=L_{s}-L_{m}$ and $L_{r l}=L_{r}-L_{m}$ are the stator and rotor leakage inductances, respectively. $\omega_{e}$ is the speed of the synchronous reference coordinate frame, $\omega_{r}$ is the electric speed of the rotor, $\omega_{s l}=\omega_{e}-\omega_{r}$ is the slip speed, and $p=d / d t$ is the differential operator. The air-gap flux is also expressed as

$$
\vec{\lambda}_{a g}^{e}=L_{m}\left(\vec{i}_{s}^{e}+\vec{i}_{r}^{e}\right)
$$


where $\vec{i}_{r}^{e}=i_{d r}^{e}+j i_{q r}^{e}$ is the rotor current. The generated electromagnetic torque of an IM is

$$
T_{e}=\frac{3 P}{4}\left(i_{q s}^{e} \lambda_{d a g}^{e}-i_{d s}^{e} \lambda_{q a g}^{e}\right)
$$

where $P$ is the number of motor poles. The mechanical equation of the motor is

$$
J_{m} p \omega_{r m}+B_{m} \omega_{r m}+T_{L}=T_{e},
$$

where $J_{m}$ is the inertia of the motor, $B_{m}$ is the viscous friction coefficient, $T_{L}$ is the load torque, and $\omega_{r m}=(2 / P) \omega_{r}$ is the mechanical speed of the motor shaft.

With the AFOC condition set at $\lambda_{\text {qag }}^{e}=0$ in Eq. (2), the estimated slip speed and $d$-axis airgap flux are derived as ${ }^{(22)}$

$$
\begin{gathered}
\hat{\omega}_{s l}=\frac{\left(1+\left(L_{r l} / R_{r}\right) s\right) i_{q s}^{e}}{\left(\tau_{r} / L_{m}\right) \lambda_{d a g}^{e}-\left(L_{r l} / R_{r}\right) i_{d s}^{e}}, \\
\frac{1+\tau_{r} s}{1+\left(L_{r l} / R_{r}\right) s} \frac{\hat{\lambda}_{d a g}^{e}}{L_{m}}=i_{d s}^{e}-\frac{\hat{\omega}_{s l} L_{r l} / R_{r}}{1+\left(L_{r l} / R_{r}\right) s} i_{q s}^{e},
\end{gathered}
$$

where "^" stands for the estimated value, $s$ is the Laplace operator, and $\hat{o}_{r}=L_{r} / R_{r}$ is the rotor time constant. The generated electromagnetic torque of an IM under an AFOC condition is acquired as

$$
T_{e}=\frac{3 P}{4} i_{q s}^{e} \hat{\lambda}_{d a g}^{e}
$$

Both the $q$-axis stator current and the estimated $d$-axis air-gap flux are orthogonal in Eq. (8). The maximum torque-to-current ratio can be attained under an AFOC condition. This superior performance is analogous to a separately excited DC motor.

Examination of Eq. (7) reveals that the $q$-axis stator current-coupling exists in the second term on the right side, defining the feed-forward compensation as

$$
i_{d_{-} q c o m p}^{e}=\frac{\hat{\omega}_{s l} L_{r l} / R_{r}}{1+\left(L_{r l} / R_{r}\right) s} L_{m} i_{q s}^{e}
$$

The linear relationship between the estimated $d$-axis air-gap flux and the $d$-axis stator current can then be obtained as 


$$
\hat{\lambda}_{\text {dag }}^{e}=\frac{1+\left(L_{r l} / R_{r}\right) s}{1+\tau_{r} s} L_{m} i_{d s}^{e}
$$

Also, set $\lambda_{\text {qag }}^{e}=0$ in Eq. (1), and the $d$ - and $q$-axis stator voltage equations under an AFOC condition are given by

$$
\begin{aligned}
& v_{d s}^{e}=\left(R_{s}+L_{s l} p\right) i_{d s}^{e}-\omega_{e} L_{s l} i_{q s}^{e}+p \lambda_{d a g}^{e}, \\
& v_{q s}^{e}=\left(R_{s}+L_{s l} p\right) i_{q s}^{e}+\omega_{e} L_{s l} i_{d s}^{e}+\omega_{e} \lambda_{d a g}^{e} .
\end{aligned}
$$

Examination of Eq. (11) reveals that the $q$-axis stator voltage coupling exists in the second term on the right side, and examination of Eq. (12) shows that the $d$-axis stator voltage coupling exists in the second and last terms on the right side. This permits the definition of $d$-and $q$-axis stator voltage feed-forward compensations, as in Eqs. (13) and (14), respectively, and the linear relationship of the $d$ - and $q$-axis stator current loops can also be obtained.

$$
\begin{gathered}
v_{d_{-} q c o m p}^{e}=-\omega_{e} L_{s l} i_{q s}^{e}+p \lambda_{d a g}^{e} \\
v_{q_{-} d c o m p}^{e}=\omega_{e}\left(L_{s l} i_{d s}^{e}+\lambda_{d a g}^{e}\right)
\end{gathered}
$$

The voltage command of the $d$ - and $q$-axis stator current loops is acquired as

$$
\begin{aligned}
& v_{d s}^{e^{*}}=v_{d s}^{e^{\prime}}+v_{d_{-} q \text { qcomp }}^{e}, \\
& v_{q s}^{e^{*}}=v_{q s}^{e^{\prime}}+v_{q_{-} d \text { dcomp }}^{e},
\end{aligned}
$$

where $v_{d s}^{e^{\prime}}$ and $v_{q s}^{e^{\prime}}$ are the outputs of the $d$ - and $q$-axis stator current controllers, respectively.

\section{Rotor Speed Estimation of an AFOC IM Drive}

The feedback speed signal is replaced by an estimated speed in the speed estimation AFOC IM drive scheme, and this estimated speed can be derived by the designed air-gap flux observer.

\subsection{Air-gap flux observer}

In the proposed speed estimation AFOC IM drive, the estimated rotor speed is derived from the air-gap flux observer, and the development of this flux observer is based on the air-gap flux 
and stator current. The difference between the actual stator current and the estimated stator current, obtained by an observer gain matrix achieves the on-line adjustment of the estimated rotor speed. The estimated stator current is acquired from the established state equations, and the actual stator current is obtained from an IM by Hall Effect current sensors.

Adaptation of Eqs. (1) and (2) with the state matrix at the stationary reference coordinate frame $\left(\omega_{e}=0\right)$ is given by

$$
\begin{aligned}
p\left[\begin{array}{c}
\hat{\vec{i}}_{s}^{s} \\
\hat{\vec{\lambda}}_{a g}^{s}
\end{array}\right] & =L_{\lambda}\left[\begin{array}{cc}
-L_{r} R_{s}-L_{m} R_{r}+j \omega_{r} L_{m} L_{r l} & R_{r}-j \omega_{r} L_{r} \\
L_{m}\left(L_{s l} R_{r}-L_{r l} R_{s}\right)-j \omega_{r} L_{m} L_{s l} L_{r l} & -L_{s l} R_{r}+j \omega_{r} L_{s l} L_{r}
\end{array}\right]\left[\begin{array}{c}
\vec{i}_{s}^{s} \\
\vec{\lambda}_{a g}^{s}
\end{array}\right] \\
& +L_{\lambda}\left[\begin{array}{c}
L_{r} \\
L_{m} L_{r l}
\end{array} \vec{v}_{s}^{s},\right.
\end{aligned}
$$

where $L_{\lambda}=1 /\left(L_{r l} L_{m}+L_{r} L_{s l}\right)$. According to Eq. (17), the air-gap flux observer is derived as

$$
\begin{aligned}
p\left[\begin{array}{c}
\hat{\vec{i}}_{s}^{s} \\
\hat{\vec{\lambda}}_{a g}^{s}
\end{array}\right] & =L_{\lambda}\left[\begin{array}{cc}
-L_{r} R_{s}-L_{m} R_{r}+j \omega_{r} L_{m} L_{r l} & R_{r}-j \omega_{r} L_{r} \\
L_{m}\left(L_{s l} R_{r}-L_{r l} R_{s}\right)-j \omega_{r} L_{m} L_{s l} L_{r l} & -L_{s l} R_{r}+j \omega_{r} L_{s l} L_{r}
\end{array}\right]\left[\begin{array}{c}
\vec{i}_{s}^{s} \\
\vec{\lambda}_{a g}^{s}
\end{array}\right] \\
& +L_{\lambda}\left[\begin{array}{c}
L_{r} \\
L_{m} L_{r l}
\end{array}\right] \vec{v}_{s}^{s}+G\left(\vec{i}_{s}^{s}-\hat{\vec{i}}_{s}^{s}\right),
\end{aligned}
$$

where $G$ is the observer gain matrix.

The proposed estimated rotor speed based on the air-gap flux observer scheme is shown in Fig. 1, in which the measured stator voltage $\vec{v}_{s}^{s}$ and the current $\vec{i}_{s}^{s}$ are obtained from the IM (by voltage and current sensors) through the coordinate transformation from 3-phase stationary

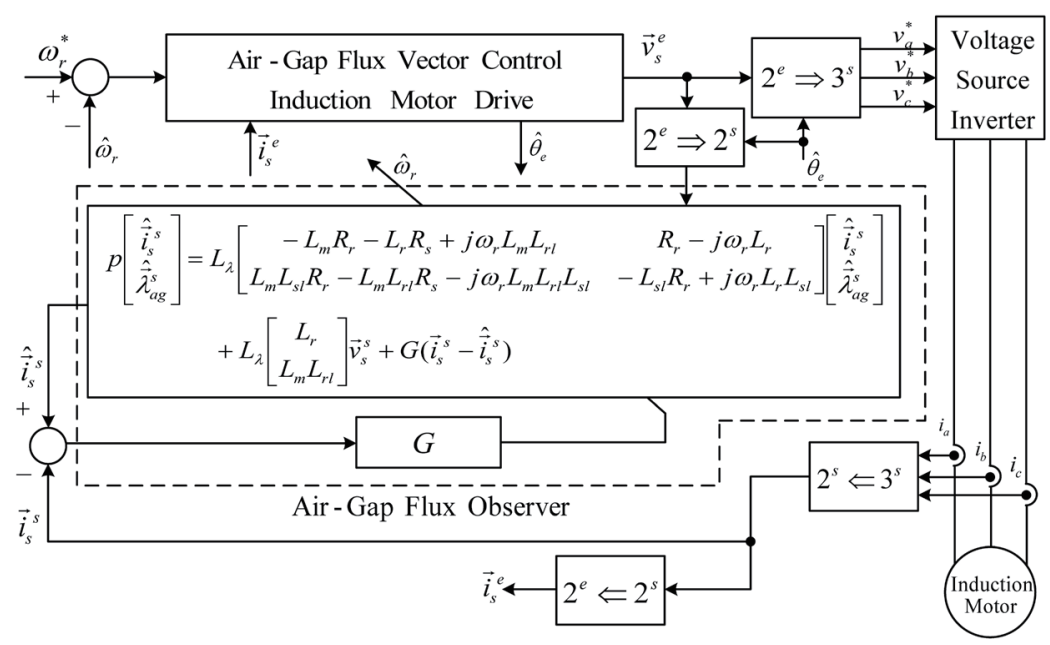

Fig. 1. Estimation of rotor speed based on the air-gap flux observer scheme. 
to 2-axis stationary $\left(2^{s} \Leftarrow 3^{s}\right)$. The estimated stator current $\hat{\vec{i}}_{s}^{s}$ is derived from the developed air-gap flux observer, and the difference between $\vec{i}_{s}^{s}$ and $\hat{\vec{i}}_{s}^{s}$ is modulated by the observer gain matrix $G$ to attain the estimated rotor speed $\hat{\omega}_{r}$, which serves as a feedback speed signal that is delivered to the AFOC IM drive.

\subsection{Lyapunov stability theory flux observer gain matrix design}

The gain matrix design of the proposed air-gap flux observer utilizes the Lyapuov stability theory. ${ }^{(23)}$ According to Eq. (17), the state equations of an IM at the stationary reference coordinate frame can be expressed as

$$
\begin{gathered}
\dot{x}=\left[A+\omega_{r} A_{\omega}\right] x+B \vec{v}_{s}^{s}, \\
y=C x,
\end{gathered}
$$

where $x=\left[\begin{array}{ll}\vec{i}_{s}^{s} & \vec{\lambda}_{a g}^{s}\end{array}\right]^{\mathrm{T}}, A=L_{\lambda}\left[\begin{array}{cc}-\left(L_{r} R_{s}+L_{m} R_{r}\right) & R_{r} \\ L_{m}\left(L_{s l} R_{r}-L_{r l} R_{s}\right) & -L_{s l} R_{r}\end{array}\right], A_{\omega}=L_{\lambda}\left[\begin{array}{cc}j L_{m} L_{r l} & -j L_{r} \\ -j L_{m} L_{s l} L_{r l} & j L_{s l} L_{r}\end{array}\right]$, $B=L_{\lambda}\left[\begin{array}{ll}L_{r} & L_{m} L_{r l}\end{array}\right]^{\mathrm{T}}$, and $C=\left[\begin{array}{ll}1 & 0\end{array}\right]$. Moreover, in accordance with Eq. (19), the estimation state matrix is derived as

$$
\dot{\hat{x}}=\left[A+\hat{\omega}_{r} A_{\omega}\right] \hat{x}+B \vec{v}_{s}^{s}+G(\hat{y}-y) .
$$

The estimation error is acquired by subtracting Eq. (21) from Eq. (19), giving

$$
\dot{e}=\left(A+\omega_{r} A_{\omega}+G C\right) e+\Delta \omega_{r} A_{\omega} \hat{x}
$$

where $e=x-\hat{x}$ and $\Delta \omega_{r}=\omega_{r}-\hat{\omega}_{r}$. The Lyapunov function is selected as

$$
V\left(e, \Delta \omega_{r}\right)=e^{T} M e+\frac{\left(\Delta \omega_{r}\right)^{2}}{\delta_{\omega}},
$$

where $M$ is a symmetric positive definite matrix, $\delta_{\omega}>0$ is a constant, and hence, $V$ is a position definite function. The time derivative of the selected Lyapunov function can be derived as

$$
\begin{aligned}
\dot{V} & =e^{T}\left[(A+G C)^{T} M+M(A+G C)+\omega_{r}\left(A_{\omega}^{T} M+M A_{\omega}\right)\right] e \\
& +\Delta \omega_{r}\left[\hat{x}^{T} A_{\omega}^{T} M e+e^{T} M A_{\omega} x\right]-\frac{2\left(\Delta \omega_{r}\right)}{\delta_{\omega}} \frac{d\left(\hat{\omega}_{r}\right)}{d t} .
\end{aligned}
$$


Set $\Delta \omega_{r}\left[\hat{x}^{T} A_{\omega}^{T} M e+e^{T} M A_{\omega} \hat{x}\right]=2\left(\Delta \omega_{r}\right) / \delta_{\omega} \cdot d\left(\hat{\omega}_{r}\right) / d t$ in Eq. (24) and the selections $G$ and $H$ guarantee that the inequality Eq. (25) is valid, and then the time derivative of the selected Lyapunov function is a negative definite function. According to the Lyapunov stability theory, Eq. (22) is asymptotically stable. Hence, the established air-gap flux observer is also asymptotically stable.

$$
(A+G C)^{T} M+M(A+G C)+\omega_{r}\left(A_{\omega}^{T} M+M A_{\omega}\right)<0
$$

Select the adaptive law as

$$
\frac{d\left(\hat{\omega}_{r}\right)}{d t}=e^{T} M A_{\omega} \hat{x}
$$

According to Eq. (26), the estimated rotor speed was derived as

$$
\hat{\omega}_{r}=K_{p a}\left[e^{T} M A_{\omega} \hat{x}\right]+\frac{K_{i a}\left[e^{T} M A_{\omega} \hat{x}\right]}{s},
$$

where $K_{p a}$ and $K_{i a}$ are adaptation gains.

\subsection{Observer gain matrix parameters using FLC strategy}

The FLC strategy was used to acquire the observer gain matrix parameters in this study because it requires no precise information about the mathematical model and it is simple and easy to implement. An FLC adjustment mechanism includes fuzzification, fuzzy knowledge base, fuzzy inference, and defuzzification; ${ }^{(24)}$ the fuzzy knowledge base also has a fuzzy set and rule base, as shown in Fig. 2. The stator current error $e_{i_{s}}$ and its derivative $\dot{e}_{i_{s}}$ are input variables, the estimated rotor speed $\hat{\omega}_{r}$ is the output variable, $K_{1}$ and $K_{2}$ are the input scaling factors, and $K_{3}$ is the output scaling factor.

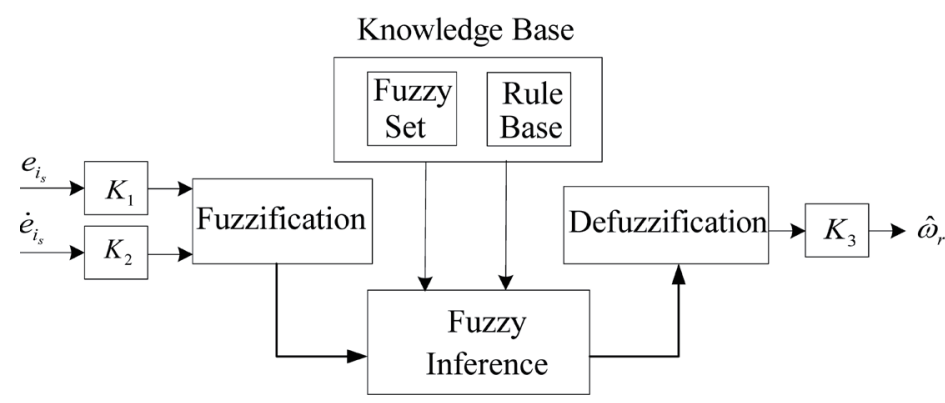

Fig. 2. An FLC adjustment mechanism. 


\subsubsection{Fuzzification}

The fuzzification function converts the crisp input values into corresponding fuzzy values, and the numbers of fuzzy sets determine the estimated speed, which is also the output of the airgap flux observer. In this system, the fuzzy set is defined as positive large (PL), positive small (PS), zero error (ZE), negative small (NS), and negative large (NL), as shown in Table 1.

The membership functions for the stator current error $\left(e_{i_{s}}\right)$, the derivative of stator current error $\left(\dot{e}_{i_{s}}\right)$, and the estimated speed $\left(\hat{\omega}_{r}\right)$ are shown in Figs. 3-5. Furthermore, $\omega_{b}$ is a base speed of the motor drive that is shown in Fig. 5.

Table 1

Fuzzy set definition.

PL Positive large

PS Positive small

ZE Zero error

NS Negative small

NL Negative large

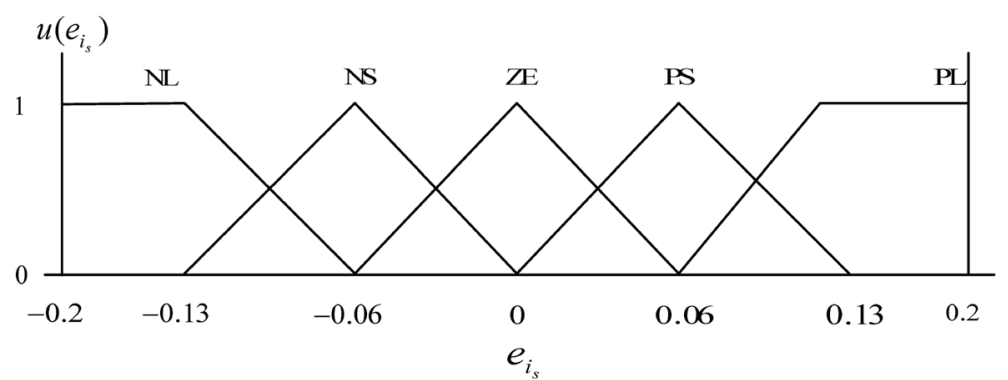

Fig. 3. Membership function of $e_{i_{s}}$.

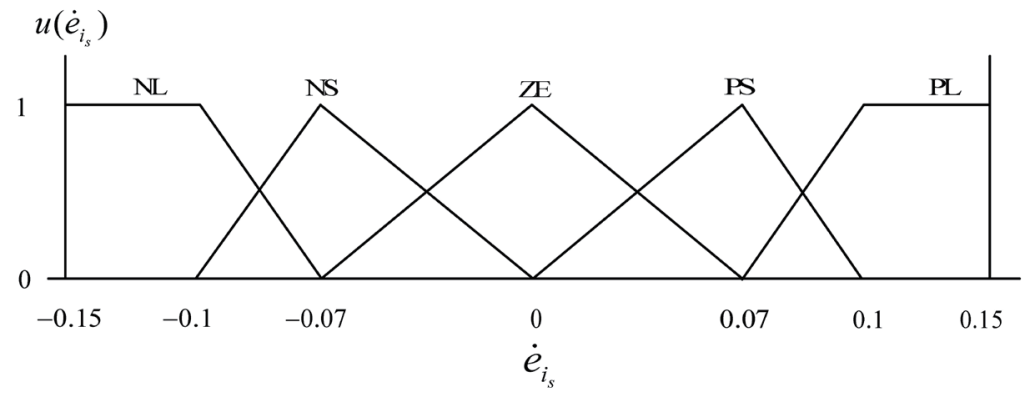

Fig. 4. Membership function of $\dot{e}_{i_{s}}$.

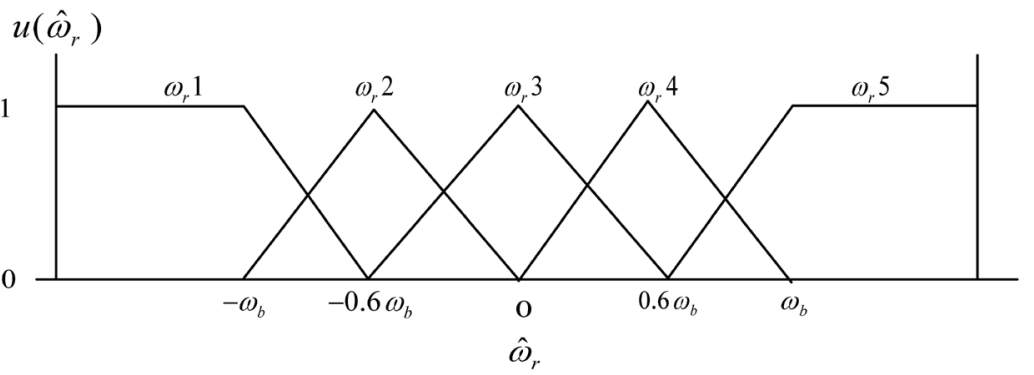

Fig. 5. Membership function of $\hat{\omega}_{r}$. 


\subsubsection{Fuzzy inference}

The output characteristic is determined by the fuzzy rule and the output measure is based on fuzzy inference. The Min-Min-Max approach was used to decide the fuzzy inference. The fuzzification step is regarded as the first Min term that uses a minimum trigger as the membership grade. The output membership grade of each fuzzy inference rule is regarded as the second Min term that selects the minimum value from the two input membership grades on the basis of the fuzzy inference rules. The maximum value approached from the same output membership functions integrated into an individual rule is regarded as the third Max term.

\subsubsection{Fuzzy rule}

The trigger of the output membership function is decided by the fuzzy rule; in this system, the linguistic term if-then is selected as the fuzzy rule. The relationship between the input variables $e_{i_{s}}$ and $\dot{e}_{i_{s}}$ and the output variable $\hat{\omega}_{r}$ is shown in Table 2.

\subsubsection{Defuzzification}

Defuzzification converts the inferred fuzzy output value into a crisp output, and the plant is controlled by this crisp output value. In this system, the central value of the defuzzification sum approach is used, giving

$$
z^{*}=\frac{\sum_{l=1}^{m} g_{l} H\left(F_{l}^{\prime}\right)}{\sum_{l=1}^{m} H\left(F_{1}^{\prime}\right)},
$$

where $H\left(F_{l}{ }^{\prime}\right)$ is the height of each $F_{l^{\prime}}$ and $g_{l}$ is the most central value of $z$ before the top of $F_{l}{ }^{\prime}$ is cut off.

The 25 fuzzy rules.

\begin{tabular}{|c|c|c|c|c|c|}
\hline \multirow{2}{*}{$\dot{e}_{i_{s}}$} & \multicolumn{5}{|c|}{$e_{i_{s}}$} \\
\hline & NL & NS & $\mathrm{NE}$ & PS & PL \\
\hline NL & $\omega_{r} 1 \quad 1$ & $\omega_{r} 1 \quad 2$ & $\omega_{r}{ }^{2} 3$ & $\omega_{r}{ }^{2} 4$ & $\omega_{r} 35$ \\
\hline NS & $\omega_{r} 1 \quad 6$ & $\omega_{r} 27$ & $\omega_{r} 28$ & $\omega_{r} 39$ & $\omega_{r}{ }^{4} 10$ \\
\hline ZE & $\omega_{r^{2}}{ }_{11}$ & $\omega_{r}{ }^{2} 12$ & $\omega_{r} 3_{13}$ & $\omega_{r} 4_{14}$ & $\omega_{r}{ }^{4} 15$ \\
\hline PS & $\omega_{r}{ }^{2} 16$ & $\omega_{r}{ }^{3} 17$ & $\omega_{r}{ }^{4}{ }_{18}$ & $\omega_{r}{ }^{4} 19$ & $\omega_{r}{ }^{5} 20$ \\
\hline PL & $\omega_{r}{ }_{21}$ & $\omega_{r}{ }^{4} 22$ & $\omega_{r} 4_{23}$ & $\omega_{r} 5_{24}$ & $\omega_{r}{ }^{5} 25$ \\
\hline
\end{tabular}


A block diagram of the proposed speed estimation AFOC IM drive with an FLC air-gap flux observer is shown in Fig. 6. It includes the speed controller, flux controller, $q$ - and $d$-axis stator current controllers, slip speed estimation, $d$-axis air-gap flux estimation, $d$-axis stator current feed-forward compensation, $d$ - and $q$-axis stator voltage feed-forward compensations, coordinate transformation, and an FLC air-gap flux observer rotor speed estimation mechanism.

In this system, the proportion-integral (PI)-type controllers for the speed control loop, flux control loop, and $d$ - and $q$-axis stator current control loops were designed by the root-locus method. The proportion gain $\left(K_{p}\right)$, integral gain $\left(K_{i}\right)$, and bandwidth $(B . W$.$) for the four PI-type$ controllers are shown in Table 3. The gain matrix parameters of the air-gap flux observer were designed using the FLC strategy.

\section{Simulation and Experiment}

The simulation scheme of the proposed speed estimation AFOC IM drive with an FLC flux observer was established using the MATLAB/Simulink ${ }^{\circledR}$ toolbox, and the execution program was realized using a TI 6713-and-F2812 DSP control card. The reversible steady-state speed commands \pm 600 and $\pm 1800 \mathrm{rpm}$ were designed to confirm the effectiveness of the transient and steady-state operation.

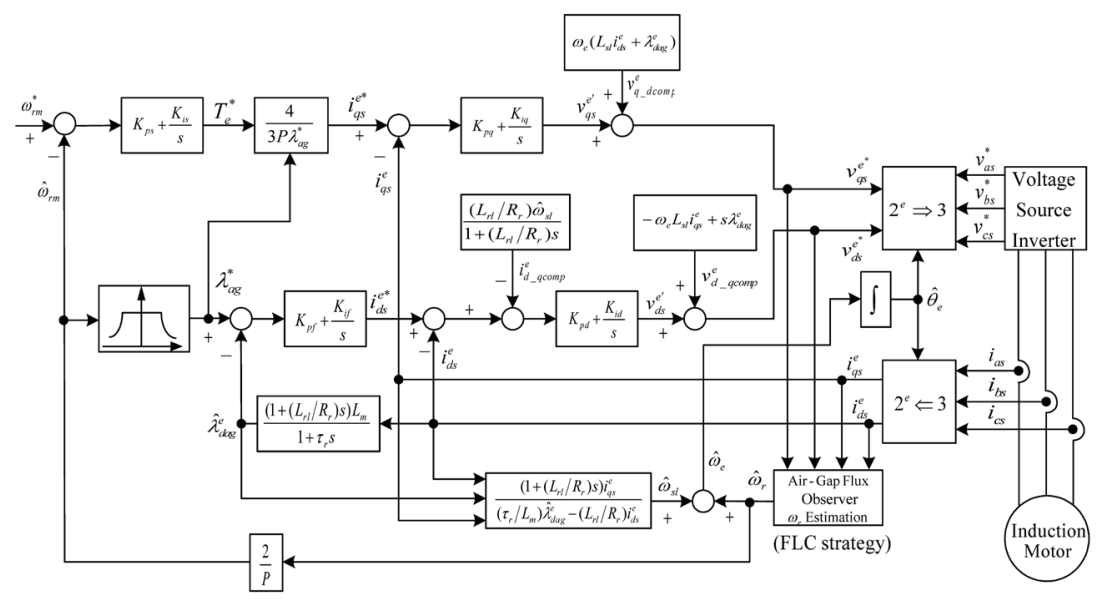

Fig. 6. Speed estimation AFOC IM drive based on an FLC flux observer.

Table 3

Controller parameters and their bandwidths.

\begin{tabular}{lccc}
\hline Controllers & $K_{p}$ & $K_{i}$ & $B . W .(\mathrm{rad} / \mathrm{s})$ \\
\hline Speed controller & 0.45 & 2.524 & 53.4 \\
Flux controller & 83.17 & 1436 & 238 \\
$d$-axis stator current controller & 6.7853 & 5785 & 1785 \\
$q$-axis stator current controller & 9.591 & 7046 & 1983 \\
\hline
\end{tabular}


A standard 3-phase, $220 \mathrm{~V}, 0.75 \mathrm{~kW}, \Delta$-connected, squirrel-cage IM was used in the experiments to confirm the effectiveness of the proposed speed estimation AFOC IM drive. In a running cycle, the speed commands used were forward direction acceleration from $t=0$ to 1 $\mathrm{s}$, forward direction steady-state running over $1 \leq t \leq 2 \mathrm{~s}$, forward direction braking operation reaching zero speed in the interval $2 \leq t \leq 3 \mathrm{~s}$, reverse direction acceleration from $t=3$ to $4 \mathrm{~s}$, reverse direction steady-state running over $4 \leq t \leq 5 \mathrm{~s}$, and reverse direction braking operation reaching zero speed in the interval $5 \leq t \leq 6 \mathrm{~s}$. The simulated and measured responses of the first running cycle are shown in Figs. 7-10. Each figure includes six responses: (a) the command (dotted line) and estimated (solid line) rotor speeds, (b) the command (dotted line) and actual (solid line) rotor speeds, (c) the electromagnetic torque, (d) the synchronous angle position, (e) the stator current, and (f) the air-gap flux locus ( $Q$-axis vs $D$-axis). The simulated and measured responses with loading $2-\mathrm{N}-\mathrm{m}$ for the reversible steady-state speed commands \pm 600 and \pm 1800 rpm are shown in Figs. 7 and 8 and Figs. 9 and 10, respectively.

From the simulated and measured responses under different operation conditions, the proposed FLC strategy air-gap observer enabled exact rotor speeds in the speed estimation AFOC IM drive. Excellent transient and steady responses that included estimated rotor speed, electromagnetic torque, synchronous angle position, stator current, and air-gap flux locus were also achieved.
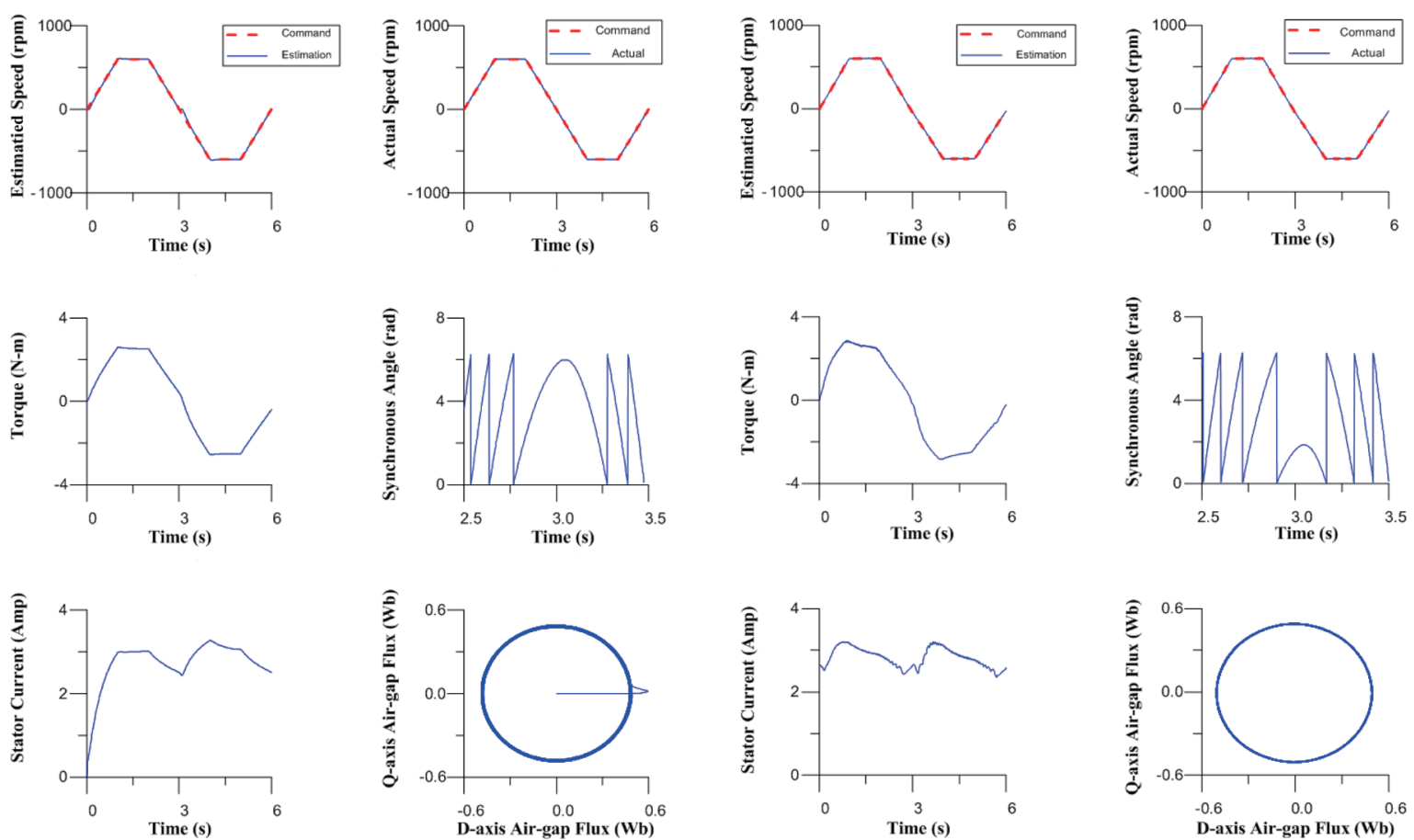

Fig. 7. (Color online) Simulated responses of the proposed speed estimation AFOC IM based on the flux observer with loading $2 \mathrm{~N}-\mathrm{m}$ at the steady-state speed command $\pm 600 \mathrm{rpm}$.

Fig. 8. (Color online) Measured responses of the proposed speed estimation AFOC IM based on the flux observer with loading $2 \mathrm{~N}-\mathrm{m}$ at the steady-state speed command $\pm 600 \mathrm{rpm}$. 

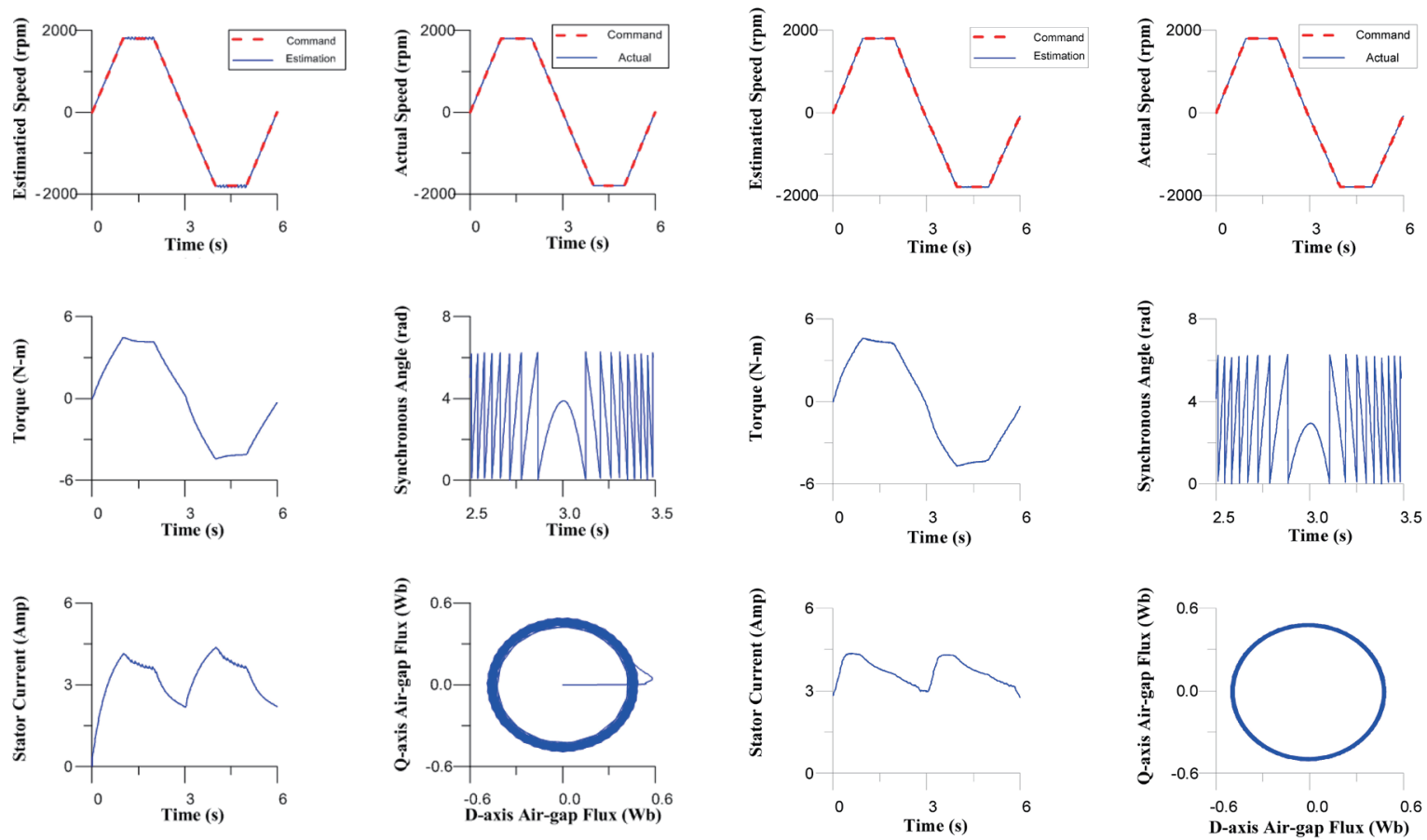

Fig. 9. (Color online) Simulated responses of the proposed speed estimation AFOC IM based on the flux observer with loading $2 \mathrm{~N}-\mathrm{m}$ at the steady-state speed command $\pm 1800 \mathrm{rpm}$.

Fig. 10. (Color online) Measured responses of the proposed speed estimation AFOC IM based on the flux observer with loading $2 \mathrm{~N}-\mathrm{m}$ at the steady-state speed command $\pm 1800 \mathrm{rpm}$.

\section{Conclusion}

A speed estimation AFOC IM drive was established by utilizing the air-gap flux observer to estimate rotor speed. The proposed air-gap flux observer was designed by utilizing the Lyapunov stability theory, and the estimated rotor speed was derived from the developed flux observer. The stator current signal measurement for implementing the AFOC IM drive and the air-gap flux observer is provided by the Hall effect current sensors. The proposed speed estimation AFOC IM drive can be properly operated at different reversible steady-state operation commands. The simulation and measured responses that included estimated rotor speed, electromagnetic torque, synchronous angle position, stator current, and air-gap flux locus confirm the excellent transient and steady-state performance of the speed estimation AFOC IM drive based on the FLC strategy air-gap flux observer that was attained.

\section{References}

1 Y. C. Luo, C. L. Tsai, and Y. P. Kuo: Sens. Mater. 30 (2018) 845.

2 S. Bozhko, S. Dymko, S. Kovbasa, and S. M. Peresada: IEEE Trans. Ind. Appl. 53 (2017) 181.

3 G. Scarcella, G. Scelba, M. Cacciato, A. Spampinato, and M. M. Harbaugh: IEEE Trans. Ind. Appl. 52 (2016) 4816.

4 G. C. Konstantopoulos, A. T. Alexandridis, and E. D. Mitronikas: IEEE Trans. Control Syst. Technol. 22 (2014) 1112. 
5 S. Yang, D. Ding, X. Li, Z. Xie, X. Zhang, and L.uchen Chang: IEEE Trans. Energy Convers. 32 (2017) 1562.

6 E. D. Azad, S. Gadoue, D. Atkinson, H. Slater, P. Barrass, and F. Blaabjerg: IEEE Trans. Power Electron. 33 (2018). 1911.

7 E. D. Azad, S. Gadoue, D. Atkinson, H. Slater, P. Barrass, and F. Blaabjerg: IEEE Trans. Power Electron. 32 (2017) 7140.

8 Y. B. Zbede, S. M. Gadoue, and D. J. Atkinson: IEEE Trans. Ind. Electron. 63 (2016) 3511.

9 M. Pucci: IET Control Theory Appl. 9 (2015) 1831.

10 J. Lee and Y. S. Kim: IET Renewable Power Gener. 10 (2016) 194.

11 S. Prakash, R. Kalpana, B. Singh, and G. Bhuvaneswari: IEEE Trans. Ind. Appl. 54 (2018) 2438.

12 X. Zhang: IEEE Trans. Veh. Technol. 62 (2013) 3010.

13 A. Merabet, A. A. Tanvir, and K. Beddek: IET Renewable Power Gener. 10 (2016) 1597.

14 J. H. Im and R. Y. Kim: IEEE Trans. Ind. Electron. 65 (2018) 5335.

15 E. Zerdali and M. Barut: IEEE Trans. Ind. Electron. 64 (2017) 4340.

16 M. S. Zaky and M. K. Metwaly: Trans. Emerg. Sel. Topics Power Electron. 4 (2016) 1416.

17 I. M. Alsofyani and N. R. N. Idris: IEEE Trans. Power Electron. 31 (2016) 3027.

18 M. Habibullah and D. D. C. Lu: IEEE Trans. Ind. Electron. 62 (2015) 6765.

19 Z. Yin, G. Li, Y. Zhang, J. Liu, X. Sun, and Y. Zhong: IEEE Trans. Power Electron. 32 (2017) 7096.

20 M. Farasat, A. M. Trzynadlowski, and M. S. Fadali: IET Electr. Syst. Transp. 4 (2014) 122.

21 S. Jafarzadeh, C. Lascu, and M. S. Fadali: IEEE Trans. Ind. Appl. 49 (2013) 92.

22 C. H. Liu: Control of AC Electrical Machines (Tunghua, Taipei, 2008) (in Chinese).

23 Y. Boutails, D. Theodoridis, T. Kottas, and M. A. Christodoulou: System Identification and Adaptive Control (Springer Verlag, Switzerland AG, 2014).

24 Y. C. Luo and W. X. Chen: Comput. Math. Appl. 64 (2012) 1206.

\section{About the Authors}

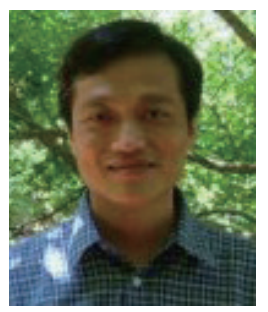

Yung-Chang Luo received his M.S. and Ph.D. degrees from National Taiwan University of Science and Technology, Taipei, Taiwan, ROC, in 1991 and 2000, respectively. He is currently an Associate Professor in the Department of Electrical Engineering, National Chin Yi University of Technology, Taichung, Taiwan, ROC. His current research interests include speed estimation of ac motor drives, front-end power factor correction of converter, and design of microcontroller-based motor drive.

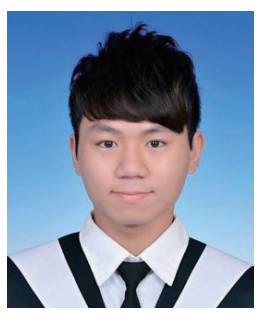

Yu-Hsiang Chen was born in April 1993. He received his Master's degree in electrical engineering from National Chin-Yi University Technology, Taiwan, in July 2017. His main research focus is on FOC IM drives.

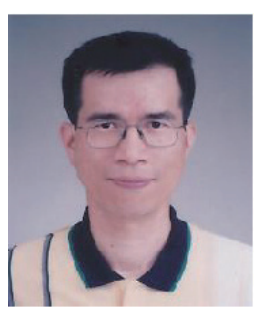

Ying-Piao Kuo received his B.S. degree in electrical engineering in 1985 from National Taiwan University of Science and Technology, Taipei, Taiwan, M.S. degree in electrical engineering in 1989 from National Taiwan University, and Ph.D. degree from National Taiwan University of Science and Technology, Taipei, Taiwan, in 2011. In 1989, he joined National Chin-Yi University of Technology, Taichung, Taiwan, where he is currently an Associate Professor in the Department of Electrical Engineering. His current research interests include design of switching-mode power supplies, partial discharge, and power system stability. 